\title{
Estimating anisotropic pollen dispersal: a case study in Quercus lobata
}

\author{
F Austerlitz ${ }^{1,6}$, C Dutech ${ }^{2,6,7}$, PE Smouse ${ }^{3}$, F Davis ${ }^{4}$ and VL Sork ${ }^{2,5}$ \\ ${ }^{1}$ Laboratoire Ecologie, Systematique et Evolution, UMR CNRS 8079, Université Paris-Sud, Orsay Cedex, France; ${ }^{2}$ Department of \\ Ecology and Evolutionary Biology, University of California Los Angeles, Los Angeles, CA, USA; ${ }^{3}$ Department of Ecology, Evolution and \\ Natural Resources, Cook College, Rutgers University, New Brunswick, NJ, USA; ${ }^{4}$ Donald Bren School of Environmental Science and \\ Management, University of California Santa Barbara, CA, USA and ${ }^{5}$ Institute of the Environment, University of California Los Angeles, \\ Los Angeles, CA, USA
}

\begin{abstract}
The pollen dispersal distribution is an important element of the neighbourhood size of plant populations. Most methods aimed at estimating the dispersal curve assume that pollen dispersal is isotropic, but evidence indicates that this assumption does not hold for many plant species, particularly wind-pollinated species subject to prevailing winds during the pollination season. We propose here a method of detecting anisotropy of pollen dispersal and of gauging its intensity, based on the estimation of the differentiation of maternal pollen clouds (TWOGENER extraction), assuming that pollen
\end{abstract}

dispersal is bivariate and normally distributed. We applied the new method to a case study in Quercus lobata, detecting only a modest level of anisotropy in pollen dispersal in a direction roughly similar to the prevailing wind direction. Finally, we conducted a simulation to explore the conditions under which anisotropy can be detected with this method, and we show that while anisotropy is detectable, in principle, it requires a large volume of data.

Heredity (2007) 99, 193-204; doi:10.1038/sj.hdy.6800983; published online 9 May 2007

Keywords: Quercus lobata; anisotropy; gene flow; neighbourhood; genetic structure; TwoGener

\section{Introduction}

Estimating the shape of the pollen dispersal distribution is a critical issue for plant population biology (Austerlitz et al., 2004), because that distribution determines the effective size of the local breeding neighbourhood (Wright, 1943). Standard estimation techniques rely on the assumption of isotropic pollen dispersal (for example, Burczyk et al., 2002; Austerlitz et al., 2004), but prevailing wind directions are rather common, and the isotropic assumption may be too limiting for windpollinated species. Few studies have been carried out that considered the subject in detail, and these are with contrasting results. On the basis of a data set of phenotypic markers (Bateman, 1947), Tufto et al. (1997) used a Brownian motion model to show that pollen dispersal in an experimental planting of maize was anisotropic. Shen et al. (1981) reported an effect of wind direction on pollen flow in a Scots pine seed orchard. Meagher et al. (2003) showed directional pollen flow in a wind-pollinated transgenic grass cultivar, Agrostis stolonifera. In contrast, others have found little anisotropy in wind-pollinated tree species (for example, Burczyk et al.,

Correspondence: Professor VL Sork, Department of Ecology and Evolutionary Biology, University of California Los Angeles, PO Box 951606, Los Angeles, CA 90095-1606, USA.

E-mail:vlsork@ucla.edu

${ }^{6}$ These authors contributed equally to this article.

${ }^{7}$ Current address: INRA-Bordeaux, UMR BIOGECO, Domaine de la Grande Ferrade-BP81, F-33883, Villenave d'Ornon, France.

Received 18 April 2006; revised 2 February 2007; accepted 19 March 2007; published online 9 May 2007
1996, 2004; Burczyk and Prat, 1997; Lian et al., 2001; Robledo-Arnuncio and Gil, 2005). Moreover, Klein et al. (2006) encountered no tendency towards anisotropy for oilseed rape, a crop species with a mixed (insect and wind) pollination system. Thus, we see that anisotropy is possible, but not inevitable.

Many population biologists have expressed concern that landscape fragmentation is decreasing the size of local populations and reducing genetic connectivity among them (for example, Ledig, 1992; Young et al., 1996; Nason et al., 1997; Couvet, 2002), and anisotropy, if present, could increase that threat. Temperate tree species may be particularly sensitive to such changes, because historical population sizes have been large, and a sudden reduction in local population size can increase the possibility of inbreeding and inbreeding depression. In addition, if the fragmented populations are spatially isolated, the lack of gene flow could contribute to a loss of genetic variation (for example, Fernández-M and Sork, 2007), especially in the long term (Lowe et al., 2005). Under other circumstances, fragmentation promotes gene flow among fragments, because the lack of vegetative cover facilitates more extensive pollen flow, especially when the fragments are not far apart (for example, Young et al., 1996). Under those conditions, anisotropy can increase gene flow among some fragments and restrict it among others.

One of the key elements of connectedness among populations will be the modelling of the pollen dispersal curve and the potential for a long tail (Nichols and Hewitt, 1994). Early methods utilized paternity analysis to model the pollen curve over a restricted sample area 
and then assigned the progeny with unidentified fathers to gene immigration (for example, Adams and Birkes 1991; Adams et al., 1992). Using variations on this basic theme, several methods have been proposed to estimate the pollen dispersal curve (for example, Burczyk et al., 1996, 2002; Smouse et al., 1999; Oddou-Muratorio et al., 2005), although not with any particular attention to the issue of anisotropy. Examination of empirical studies (for example, Streiff et al., 1999; Burczyk et al., 2002; Meagher and Vassiliadis, 2003), suggests that individual maternal trees will receive the majority of their pollen from local pollen donors, the rest of the pollen being contributed by many individuals located further away. None of these studies examined the variance in the dispersal curve owing to anisotropy; yet this factor could interact with connectivity by either increasing or decreasing the variance in dispersal, depending on the direction.

Despite the value of paternity analysis in describing the pattern of pollen dispersal, it requires a large sampling effort, involving the maximum possible fraction of the potential fathers of a given set of seeds, which makes it difficult to sample on a landscape scale (Sork et al., 1999; Smouse and Sork, 2004; but see OddouMuratorio et al., 2005). To improve the scale of sampling and to provide an alternative method for the instances where genetic resolution is limited and/or where enumeration and sampling of the bulk of the paternal candidates is not feasible, an alternative method (dubbed TWOGENER) has been developed (Smouse et al., 2001). This method consists of computing the genetic differentiation between the pollen clouds of a large sample of mothers, physically spread across the landscape, and it requires only the genotypes of these mothers, along with those of a sample of seeds from each of them. Assuming an isotropic pollen dispersal curve that is either exponential or normal, this method can be used to estimate the average distance of pollen dispersal (Austerlitz and Smouse, 2001). We subsequently extended this TWOGENER approach to estimate the mean dispersal distance $(\delta)$ parameter, along with the effective density of reproductive adults, $d_{\mathrm{e}}$ (Austerlitz and Smouse, 2002). In a more recent effort, we have extended the treatment to estimate both scale and shape parameters of the dispersal curve, by extending the isotropic treatment to several two-parameter families, in particular the exponential power family of distributions (Austerlitz et al., 2004). Empirical studies show that paternity and TwOGENER analyses yield similar estimates (Austerlitz et al., 2004; Burczyk and Koralewski, 2005), but we have no idea of the bias that may occur when these isotropic methods are used in situations of strongly directional pollen dispersal.

Our main objective in this paper is to develop an anisotropic extension of the TWOGENER dispersal-curve extraction, which allows us to infer both the major axis of pollen dispersal, and the standard deviation of dispersal along this axis, as well as that along the orthogonal axis, assuming that pollen dispersal follows a bivariate normal distribution that is anisotropic. We also develop a permutation method that allows us to test the significance of this estimate. We then apply this method to test for wind-related anisotropy in a population of Quercus lobata occurring in an oak-Savannah ecosystem of southern California. Finally, we perform a simulation study, which is by no means exhaustive, but which evaluates the extent to which anisotropy can be detected in a design such as that we have used here. The parameters of our simulated populations were chosen to be as close as possible to those of the study population and to test these parameters under similar and contrasting spatial arrays of trees, so that we can assess both the bias and precision (variance) of our estimates under natural conditions and the power and robustness of our permutation method.

We apply this approach to anisotropic pollen movement to California valley oak (Q. lobata), a threatened tree species from the Central Valley of California that has undergone dramatic demographic attrition owing to habitat conversion and low adult recruitment rates in remaining populations since early European settlement in the 19th century (Pavlik et al., 1991). The species now occurs mainly in open savannahs in valleys and foothills of the Coast Ranges and Sierra Nevada mountains, and to a lesser extent in narrow gallery forests of the Central Valley. Conservation of this species has become a priority for the State of California, and estimation of gene flow rates and distances are a prerequisite for effective management of its genetic diversity. Our studies indicate that average pollen dispersal distance for savannah populations of $Q$. lobata ranges between 64 to $350 \mathrm{~m}$, the precise value depending on the family of dispersal curves assumed, as well as the estimate of the effective adult reproductive density, $d_{e}$ (Sork et al., 2002; Austerlitz et al., 2004). Because of the low adult density, all the estimates indicate a small reproductive neighbourhood size.

This wind-pollinated species seems a possible candidate for directional pollen movement. Detailed anemometer data from a nearby meteorological station document strong prevailing winds during the pollination season (Dutech et al., 2005). If wind direction has a significant effect, the orientation of populations and the primary direction of pollen flow should be taken into account in estimating the effective number of pollen donors per female tree. In a separate study of spatial genetic pattern of adults at this same study site, Dutech et al. (2005) found suggestive (though non-significant) evidence of anisotropic spatial autocorrelation. Those adults were all established between 400 and 100 years ago, and the population has experienced a long period of gradual demographic attrition, so we speculated that an initial anisotropic signature might well have decayed over time and that we might expect to find a stronger 'wind signature' among new recruits (Dutech et al., 2005).

\section{Methods}

\section{Anisotropic TwOGENER}

In the interest of mathematical tractability, we restrict ourselves here to the case of the bivariate anisotropic normal pollen dispersal kernel. Our previous studies have shown that it is clearly not the best-fitting curve in many cases (Austerlitz et al., 2004), but the possibility of deriving explicit closed-form formulas makes it a tractable starting point for any attempt to develop a method of detecting anisotropy, without resorting to strictly numerical analysis. This pollen dispersal distribution is characterized by three parameters, $\alpha, \sigma_{\max }$ 
and $\sigma_{\min }$. The first parameter $(\alpha)$ corresponds to the angle between the north-south axis and the major axis of observed pollen dispersal (rotating clockwise). The second is the standard deviation $\left(\sigma_{\max }\right)$ of pollen dispersion along this major axis, and the third is the standard deviation $\left(\sigma_{\mathrm{min}}\right)$ of pollen dispersion along the minor (perpendicular) axis.

As an angle between two axes, $\alpha$ can take values between $0^{\circ}$ and $180^{\circ}$ ( 0 to $\pi$ radians). For a windpollinated species, the natural expectation is that the major axis of pollen flow $(\alpha)$ should be similar to that of the prevailing wind direction. More precisely, we assume that pollen disperses with equal probability to any point of an ellipse, for which the major axis makes an angle $\alpha$ with the $Y$ axis and for which dispersion along the major and minor axes are proportional to the values of $\sigma_{\max }$ and $\sigma_{\min }$ respectively (Figure 1 ). The classical equations describing an ellipse in a Cartesian system yield

$$
\begin{aligned}
p\left(\alpha, \sigma_{\min }, \sigma_{\max } ; x, y\right) & \frac{1}{2 \pi \sigma_{\max } \sigma_{\min }} \exp \left[-\left(\frac{(-x \cos (\alpha)+y \sin (\alpha))^{2}}{2 \sigma_{\min }^{2}}\right.\right. \\
& \left.\left.+\frac{(x \sin (\alpha)+y \cos (\alpha))^{2}}{2 \sigma_{\max }^{2}}\right)\right] .
\end{aligned}
$$

When $\sigma_{\max }=\sigma_{\min }$, all terms containing the angle $\alpha$ cancel, reducing Equation (1) to its isotropic bivariate form, where pollen disperses with equal probability to any point on a circle around the origin. We computed the average dispersal distance $\delta$ (integrated around the ellipse) for the anisotropic distribution, using MATHEMATICA (Wolfram, 1999), as

$$
\begin{aligned}
\delta & =\int_{-\infty}^{\infty} \int_{-\infty}^{\infty} \sqrt{x^{2}+y^{2}} p\left(\alpha, \sigma_{\min }, \sigma_{\max } ; x, y\right) d x d y \\
& =\sqrt{\frac{2}{\pi}} \sigma_{\max } E\left(1-\frac{\sigma_{\min }^{2}}{\sigma_{\max }^{2}}\right),
\end{aligned}
$$

where $E(m)$ denotes the complete elliptic integral, defined as

$$
E(m)=\int_{0}^{\pi / 2}\left(1-m \sin ^{2}(x)\right)^{1 / 2} d x,
$$

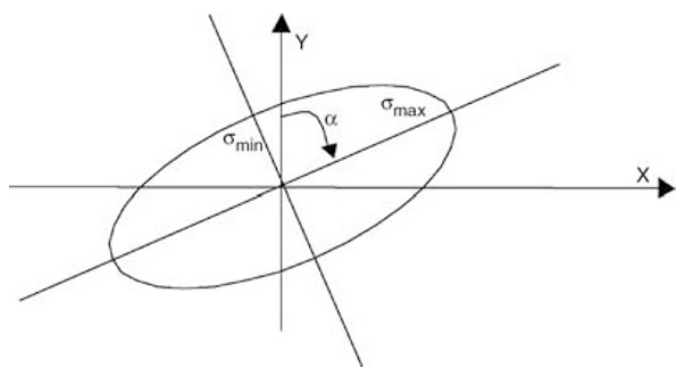

Figure 1 Schematic representation of the dispersal parameters of the dispersal curve. The probability of pollen dispersal is the same for every point on the represented ellipse. $\alpha, \sigma_{\max }$ and $\sigma_{\min }$ correspond, respectively, to the major dispersal axis, the standard deviation of dispersal along this major axis and the standard deviation of dispersal along the minor axis. for any nonnegative $m$ value. While $\delta$ cannot be computed in closed form, numerical integration is easily accomplished, and the MATHEMATICA software program does that routinely, with the function EllipticE. This integration is also performed automatically in the software program that we provide (see below), which does not require the installation of MATHEMATICA.

As in our previous studies, the estimates that we develop here are based on the TwOGENER method (Smouse et al., 2001), where the level of differentiation $\left(\phi_{i j}\right)$ between the pollen clouds is computed for all pairs of females for which seeds have been sampled in the population (Austerlitz and Smouse, 2002; Austerlitz et al., 2004). For each of these pairs, the observed level of pollen pool genetic differentiation $\left(\phi_{i j}\right)$ is compared with the theoretical level of differentiation expected between these two females, a distance $z_{i j}$ apart. For isotropic distributions, the theoretical expectation for $\phi_{i j}$ value between the $i$ th and $j$ th females is dependent only on the parameters of the dispersal curve, the effective adult reproductive density $\left(d_{\mathrm{e}}\right)$ and the physical distance $\left(z_{i j}\right)$ between them (Austerlitz et al., 2004). Where direction matters, this theoretical $\phi_{i j}$ will also depend on the angle $\left(\theta_{i j}\right)$ made by the line that joins these two females, relative to the $Y$ axis (see Figure 2).

The equation for the pairwise $\phi_{i j}$ for two females at distance $z_{i j}$, making an angle $\theta_{i j}$ with the $Y$ axis is computed, following Austerlitz and Smouse (2001), as

$$
\begin{aligned}
& \phi_{i j}\left(d, \alpha, \sigma_{\min }, \sigma_{\max }, z_{i j}, \theta_{i j}\right) \\
& =\frac{Q_{0}\left(d, \alpha, \sigma_{\min }, \sigma_{\max }\right)-Q\left(d, \alpha, \sigma_{\min }, \sigma_{\max }, z_{i j}, \theta_{i j}\right)}{2-Q\left(d, \alpha, \sigma_{\min }, \sigma_{\max }, z_{i j}, \theta_{i j}\right)},
\end{aligned}
$$

where $Q_{0}\left(d, \alpha, \sigma_{\min }, \sigma_{\max }\right)$ is the probability that two male gametes, sampled from the pollen cloud of the same female, were drawn from the same father; $Q\left(d, \alpha, \sigma_{\min }, \sigma_{\max }, z_{i j}, \theta_{i j}\right)$ the probability that two male gametes, sampled from the pollen clouds of the $i$ th and $j$ th females, were from the same father. It develops that $Q_{0}\left(d, \alpha, \sigma_{\min }, \sigma_{\max }\right) \quad$ can be computed directly, using Equation (10) from Austerlitz and Smouse (2001) as

$$
\begin{aligned}
& Q_{0}\left(d, \alpha, \sigma_{\min }, \sigma_{\max }\right) \\
& =\frac{1}{d} \int_{-\infty}^{\infty} \int_{-\infty}^{\infty} p^{2}\left(d, \alpha, \sigma_{\min }, \sigma_{\max }, x, y\right) d x d y,
\end{aligned}
$$

where $p\left(\alpha, \sigma_{\min }, \sigma_{\max } ; x, y\right)$ is the dispersal distribution defined in Equation (1). $Q\left(d, \alpha, \sigma_{\min }, \sigma_{\max }, z_{i j}, \theta_{i j}\right)$ can be

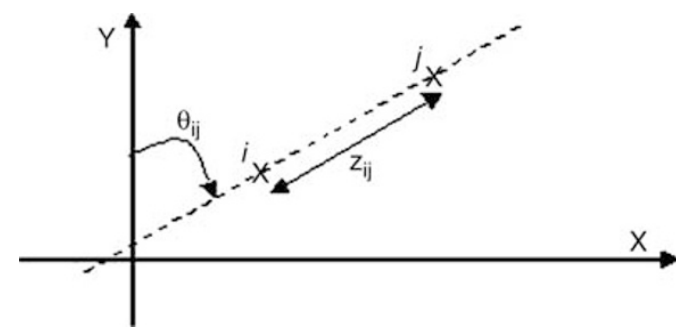

Figure 2 The two physical quantities that are computed between the $i$ th and $j$ th mothers, their physical distance of separation $\left(z_{i j}\right)$ and the angle they make with the $Y$ axis $\left(\theta_{i j}\right)$. 
computed as

$$
\begin{aligned}
& Q\left(d, \alpha, \sigma_{\min }, \sigma_{\max }, z_{i j}, \theta_{i j}\right) \\
& =\frac{1}{d} \int_{-\infty}^{\infty} \int_{-\infty}^{\infty} p\left(d, \alpha, \sigma_{\min }, \sigma_{\max }, x, y\right) \\
& \quad \times p\left(d, \alpha, \sigma_{\min }, \sigma_{\max }, x+z_{i j} \cos \left(\theta_{i j}\right), y+z_{i j} \sin \left(\theta_{i j}\right)\right) d x d y
\end{aligned}
$$

Note that, as in our previous models (Austerlitz and Smouse, 2001; Austerlitz et al., 2004), Equations (3) and (4) are based on the assumptions that the reproductive trees are randomly distributed on the landscape, following a point process pattern. We also assume that these adults are not inbred, and that there is also no biparental inbreeding. The integrals involved in Equations (4-5) are computable analytically, using Mathematica 4.1, and their expressions can be inserted into Equation (3), yielding (after further simplification):

$$
\left.\begin{array}{l}
\phi_{i j}\left(d, \alpha, \sigma_{\min }, \sigma_{\max }, z_{i j}, \theta_{i j}\right) \\
=1-\left[\frac{8 \pi d \sigma_{\max } \sigma_{\min }-1}{z_{i j}^{2}\left[\sigma_{\max }^{2}+\sigma_{\min }^{2}\right.}\right], \\
8 \pi d \sigma_{\max } \sigma_{\min }-\exp \left\{-\frac{\left.-\left(\sigma_{\max }^{2}-\sigma_{\min }^{2}\right) \cos \left(2\left(\alpha-\theta_{i j}\right)\right)\right]}{8 \sigma_{\max }^{2} \sigma_{\min }^{2}}\right\}
\end{array}\right]
$$

The dispersal parameters $\alpha, \sigma_{\max }$ and $\sigma_{\min }$ can be estimated by numerically minimizing the squared-error loss criterion for the choice of these parameters,

$$
\begin{aligned}
& C\left(d, \alpha, \sigma_{\min }, \sigma_{\max }\right) \\
& =\sum_{i<j}^{n_{\mathrm{m}}}\left(\phi_{i j}^{\mathrm{obs}}-\phi_{i j}\left(d, \alpha, \sigma_{\min }, \sigma_{\max }, z_{i j}, \theta_{i j}\right)\right)^{2}
\end{aligned}
$$

where $n_{\mathrm{m}}$ is the number of sampled mothers. The effective reproductive density (d) can be set to a fixed value, usually the adult census density of the population, or it can be estimated jointly with the dispersal parameters. The standard deviation of each estimate was computed by jack-knifing among loci (Weir, 1996).

The level of anisotropy was computed as the ratio $R_{\mathrm{a}}=\sigma_{\max } / \sigma_{\min }$. Two $R_{\mathrm{a}}$ values can be estimated, one $\left(\hat{R}_{a 1}\right)$ with $d$ fixed at the census density and one $\left(\hat{R}_{a 2}\right)$ with $d$ jointly estimated. We tested the significance of both $\hat{R}_{a}$ values with a simulation approach. For this, we estimated their null distribution by generating 1000 simulated data sets based on the hypothesis of isotropic dispersal. The simulations were performed with the simulation method described below, using as inputs the spatial positions of the mothers and the potential fathers (including the non-genotyped ones) and the genotypes of the mothers. For the potential fathers, the genotypes were completed when partially known or created when completely unknown, by drawing their alleles at each locus according to the estimated allelic frequencies within the population. For the null distribution of $R_{\mathrm{a} 1}$, the simulations were performed assuming an isotropic normal distribution with parameter $\sigma_{1}$, where $\sigma_{1}$ represents the estimated value of $\sigma$ from TWOGENER assuming an isotropic dispersal and fixed density. For $R_{\mathrm{a} 2}$, we used an isotropic normal distribution with parameter $\sigma_{2}$, where $\sigma_{2}$ represents the estimated value of $\sigma$ from TWOGENER assuming an isotropic dispersal with density jointly estimated. Then, the tail probability of each estimated $\hat{R}_{a}$ value was computed as the proportion of values in the null distributions that were above the actual data result. Note that this method requires the spatial positioning of the adults several hundreds of metres around the sampled mothers, but not their genotyping.

Note also that the pollen dispersal distribution given in Equation (1) is centred on zero. It means that, while we can predict a main axis of pollen dispersal, we cannot predict directionality. For instance, we can say that the main dispersal axis makes a $10^{\circ}$ angle with the NorthSouth axis, but we cannot assess whether the main wind comes from the south or the north. This constraint comes from the symmetry in the TWOGENER pairwise $\Phi_{\mathrm{ft}}$ coefficients: for each pair of mothers $A$ and $B$, we can compute only one $\Phi_{\mathrm{ft}}$ value, and this value will be the same whether the wind blows mostly from $A$ to $B$ or from B to A.

Software programs for all of the methods described here are available in the POLDISP package (Robledo-Arnuncio et al., in press), available at http://poldisp.googlepages.com/.

\section{A case study in Valley oak}

\section{Study site and sampling regime}

The study site is located at the U.C. Santa Barbara University of California's Sedgwick Reserve, along Figueroa Creek $\left(34^{\circ} 42^{\prime} \mathrm{N}, 120^{\circ} 02^{\prime} \mathrm{W}\right), 10 \mathrm{~km}$ northeast of Santa Ynez, in Santa Barbara County, California (Sork et al., 2002). Valley oaks at our study site occupy deep

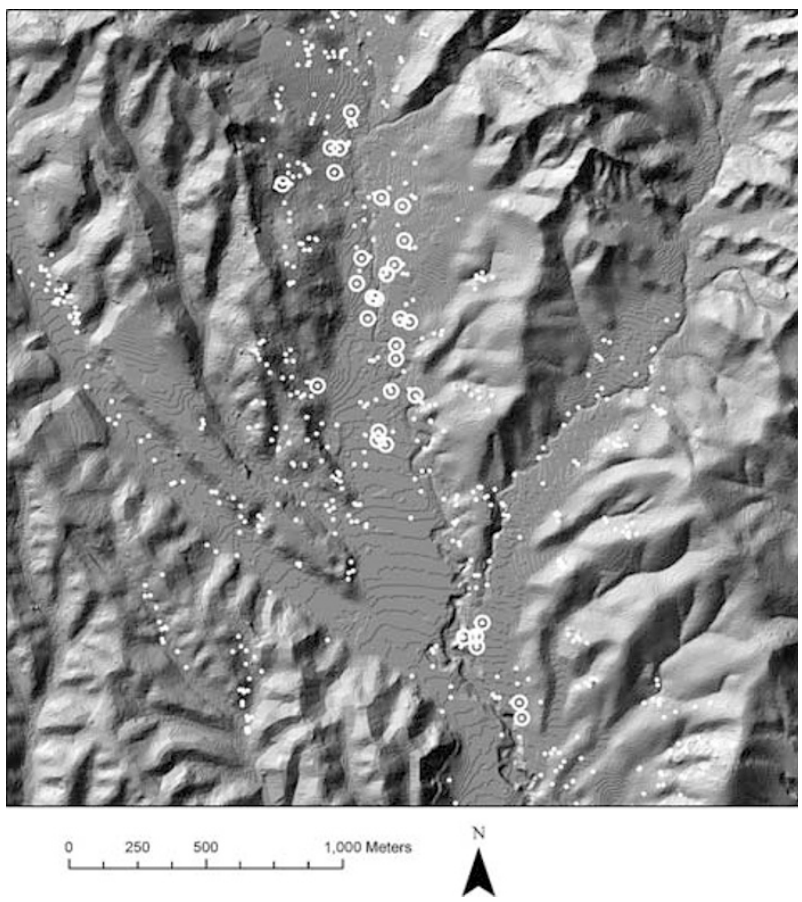

Figure 3 Map of the study population in Figueroa Valley at Sedgwick Reserve, Santa Barbara Co., CA, USA, with all adult trees indicated by white dot and sampled trees circled. 
alluvial soils on the valley floor and adjacent hill slopes, at elevations ranging from 300 to $400 \mathrm{~m}$ above sea level (Figure 3 ). The valley is oriented roughly $5^{\circ}-10^{\circ}$ west-ofnorth to east-of-south, and is bounded by ridges ranging in elevation from 440 to $475 \mathrm{~m}$ above sea level. The current adult stem density of Valley oak in the study area averages about 1.19 trees/ha at Figueroa Creek, and most individuals are greater than $85 \mathrm{~cm}$ diameter at breast height, representing adults that are probably at least 150 years of age.

Since 1997, the Sedgwick Reserve has maintained a weather station located on a level terrace, approximately $1 \mathrm{~km}(750-1500 \mathrm{~m})$ west of our study population. We analysed hourly average wind speed and direction for daytime hours (0900-1800, PST) during the main flowering period of 1 March to 30 April 2001, the year of this study (Figure 4). During the flowering period, wind speeds averaged $3.2 \pm 1.6 \mathrm{~m} / \mathrm{s}$, with maximum hourly averages of $7-8 \mathrm{~m} / \mathrm{s}$. The wind rise shows the strong directionality of winds from the west-northwest, the main wind axis being $290^{\circ}$, which is true for most lowelevation locations in the Santa Ynez Valley (see for example, Ogden, 1975). Relative to the weather station, wind speeds in the study area may be reduced slightly by the sheltering effect of local topography, but the direction should be much the same.

In the fall of 2001, we sampled acorns from as many trees as possible in the Figueroa Creek area, obtaining seeds from 31 maternal trees (Figure 3). The average distance between sampled maternal trees was $865 \mathrm{~m}$; minimum distance was $13 \mathrm{~m}$ and maximum distance was $3198 \mathrm{~m}$. The collected acorns were conveyed to the University of Missouri (St Louis, CA, USA) and planted in a greenhouse for germination. We collected one leaf per seedling for DNA analysis. The number of seedlings analysed per family ranged from 5 to 12 (mean $=8.72$ ).

\section{DNA analysis}

We extracted total DNA from 30 to $40 \mathrm{mg}$ of leaf tissue from each individual (offspring and mother trees), using a CTAB (cetyltrimethylammonium bromide) buffer and

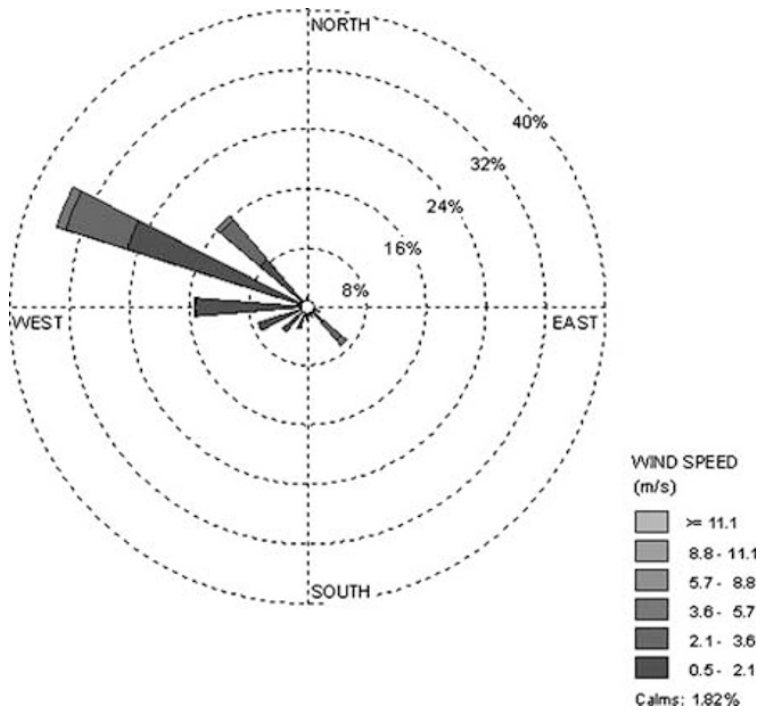

Figure 4 Wind rose describing the direction and velocity of wind during the main flowering period of the study year 2001 between 0010 and 0018 . liquid nitrogen, following the method described in Sork et al. (2002). We utilized a battery of six microsatellite loci, originally developed from other oak species: QrZAG20, QpZAG36, QpZAG46 and QpZAG110 developed by Steinkellner et al. (1997) from $Q$. robur and Q. petraea; MSQ4 developed by Dow et al. (1995) from Q. macrocarpa; JFF58, which is a redesign of the QpZAG58 primer pair (Steinkellner et al., 1997) performed by JF Fernández-M (unpublished data). The sequence of the new forward primer is ATCCATTATCTGCAAGATTC and the reverse primer is TCTTCTCTTTTCTTTTTCCT. QrZAG20, QpZAG36, QpZAG110 and MSQ4 were used to describe spatial genetic structure of adults at Sedgwick Reserve (Dutech et al., 2005). We used PCR methods and visualization on denaturing acrylamide gels, as described by Sork et al. (2002), to reveal polymorphism at these microsatellite loci. We genotyped all 31 mothers and their offspring for these six loci, along with 57 other adults, to have a reliable estimate of allelic frequencies for each of the loci, needed for the TWOGENER analysis.

\section{Empirical results}

The global differentiation of the pollen clouds was low $\left(\Phi_{\mathrm{ft}}=0.040\right)$. First assuming isotropic dispersal and setting effective reproductive density equal to average adult density (d) for our Figueroa Creek site $(d=1.19$ trees/ha), we estimated an isotropic normal dispersal standard deviation for pollen dispersal of $\hat{\sigma}=88.6 \mathrm{~m}$, which corresponds to a mean dispersal distance $(\hat{\delta})$ of $111 \mathrm{~m}$ (Austerlitz and Smouse, 2001). The joint estimation of effective density and dispersal distance yielded a larger value for dispersal distance ( $\hat{\sigma}=193 \mathrm{~m}, \hat{\delta}=242 \mathrm{~m})$, along with an estimated effective density $\left(\hat{d}_{\mathrm{e}}\right)$ of 0.616 individuals per ha, so $\left(\hat{d}_{\mathrm{e}} / d\right)=\sim 0.5$.

Using the anisotropic Gaussian dispersal model described above, we obtained an estimate of the angle made by the major dispersal axis with the north axis $(\hat{\alpha})$ of $154^{\circ} \pm 2.63^{\circ}$, along with a standard deviation of dispersal, along this axis $\left(\hat{\sigma}_{\max }\right)$ of $185 \pm 29 \mathrm{~m}$, as well as a minor axis $\hat{\sigma}_{\text {min }}$ of $42 \pm 3 \mathrm{~m}$ (Figure 5). From Equation (2), these estimates yielded an estimated mean pollen dispersal distance of $\hat{\delta}=151 \pm 22 \mathrm{~m}$, slightly above the value obtained with isotropic dispersal. The estimated ratio of standard deviations, $\hat{R}_{a}=\left(\hat{\sigma}_{\max } / \hat{\sigma}_{\min }\right)$ was 4.39 , not significant $(P=0.4)$ with the permutation method. When density was jointly estimated with the dispersal parameters, it was estimated to be $\hat{d}_{\mathrm{e}}=0.674 \pm 0.399$ trees/ha, and using that as our density estimate, we
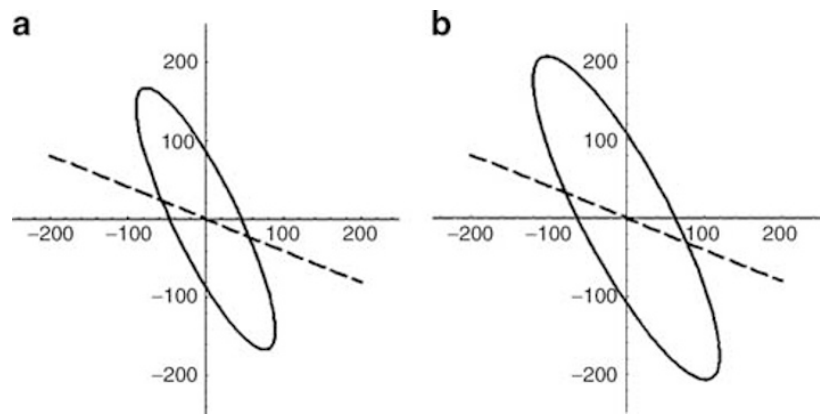

Figure 5 Elliptic representation of the dispersal function (see Figure 1) where density is set at its fixed value. The dashed line represents the main wind direction (see Figure 4). 
obtained $\hat{\sigma}_{\max }=233 \pm 224 \mathrm{~m}, \hat{\sigma}_{\min }=56 \pm 12 \mathrm{~m}, \hat{\alpha}=152^{\circ} \pm$ $7.22^{\circ}$ and $\delta=264 \pm 178 \mathrm{~m}$. These figures yield $\hat{R}_{a}=4.12$, also not significant $(P=0.43)$.

\section{Simulation study}

\section{Procedures}

We performed a simulation study, designed to mimic the Valley oak study, to assess the power and robustness of the anisotropic analysis. We simulated a spatially explicit population of 314 individuals (the number of adults at the Figueroa Creek site; see Figure 3). All individuals were characterized according to their spatial coordinates and their genotypes at the six loci used above. The spatial coordinates were strictly the same as in the study population. We had the complete six-locus genotypes of the 88 individuals ( 31 mothers and 57 other adults) that we used for the empirical analysis above. We had another 162 adults with only four of the six loci from Dutech et al. (2005). These four-locus genotypes were held as is, with the other two loci being drawn at random from a Hardy-Weinberg gene pool formed with the allelic frequencies from the 88 previous individuals. We had another 160 for which we had spatial locations, but no genotypes, and for these, we drew six-locus genotypes from the Hardy-Weinberg gene pool. We also had a few holes in the data (missing loci), which were filled by random draws from the Hardy-Weinberg gene pool.

Then we simulated progenies for a given number $\left(n_{\mathrm{m}}\right)$ of chosen mothers, following the procedure explained by Austerlitz and Smouse (2002). Briefly, assume that pollen follows a dispersal distribution $p(\Omega ; x, y)$, where $\Omega=$ $\left\{\alpha, \sigma_{\max }, \sigma_{\min }\right\}$ is the set of dispersal parameters under discussion. We assumed equal male fecundities, so that the pollination probabilities were determined by the array of intermate distances only. The likelihood, $p_{\text {mi }}$, of the male at position $\left(x_{i}, y_{i}\right)$ providing the gamete fertilizing an ovule for a female at position $\left(x_{\mathrm{m}}, y_{\mathrm{m}}\right)$ is

$$
p_{\mathrm{m} i}=\frac{p\left(\Omega ; x_{i}-x_{\mathrm{m}}, y_{i}-y_{\mathrm{m}}\right)}{\sum_{j=1}^{n} p\left(\Omega ; x_{j}-x_{\mathrm{m}}, y_{j}-y_{\mathrm{m}}\right)},
$$

which assumes that the probability of fertilizing a given female depends only on the distance to that female, and so that every individual has the same male fertility. The genotype of the resulting offspring is constituted by first drawing its father, according to the $p_{\mathrm{m} i}$, and then assigning a pair of gametes, one from each parent, in Mendelian proportions.

We performed simulation analyses of three different dispersal functions. First, we used an anisotropic dispersal model, with parameters $\alpha=154^{\circ}, \sigma_{\max }=186 \mathrm{~m}$ and $\sigma_{\min }=42 \mathrm{~m}$, as estimated from the empirical data (see Case study). Second, we used a dispersal function with the same values of $\sigma_{\max }$ and $\sigma_{\min }$, but with an angle $\alpha=64^{\circ}$, orthogonal to that major axis, to determine whether we could have detected anisotropy had the major axis been rotated $90^{\circ}$. This rotation tests whether our observed result was an artifact of the peculiar spatial arrangement of trees in our sample, which differs to some extent from the random spatial point process assumed in Equations (4) and (5). Indeed the distribution of the trees in our population is not random, because most mother trees sampled here are situated along a
North-South line, running roughly down the valley and also close to the main wind direction (see Figures 3 and 4). Thus, this rotation allows us to assess whether the particular orientation of the trees, relative to the main wind direction could generate some bias. Third, to determine how often spurious anisotropy would be detected in the isotropic case (type-I error rate), we used an isotropic dispersal distribution with $\sigma=125 \mathrm{~m}$ (set to the same average dispersal distance as for the first case).

To assess the effects of the number of mothers sampled $\left(n_{\mathrm{m}}\right)$ and of the progeny size per mother $\left(n_{\mathrm{p}}\right)$, we assumed either $n_{\mathrm{m}}=31$ or 62 and $n_{\mathrm{p}}=20$ and 40 . For $n_{\mathrm{m}}=31$, we used the 31 mothers of the experimental studies, whereas for $n_{\mathrm{m}}=62$, we added 31 mothers drawn at random (the same for all the simulations). This simulation allowed us to determine whether accuracy was augmented more by doubling the number of sampled mothers or their progeny sizes.

We performed repeated simulations (1000 replicates) for each case. For each simulated data set, we first estimated $\sigma$ for the isotropic bivariate normal case, with adult density fixed either at its observed value or estimated jointly with the dispersal parameters. Second, we estimated the anisotropic parameters, either setting density at its observed value or estimating it jointly with the dispersal parameters. For all simulations, we computed the bias, standard deviation and the root mean-squared error $(\sqrt{\mathrm{MSE}})$ of the estimates. Then, for each simulated data set, we computed the ratio $R_{\mathrm{a}}$ of major to minor axis $\sigma$ estimates, both with density set at its observed value and jointly estimated with the other parameters. We applied the simulation based testing method to each of these simulated data sets, allowing us to determine the proportion of cases in which anisotropy was detected at the $5 \%$ level, both in situations where dispersal was truly anisotropic and in situations where it was not, to assess both type-I and type-II error rates, thus evaluating both the power and robustness of our treatment.

\section{Results}

Consider first the case (Table 1), for which we used parameters similar to those estimated from the field study $\left(\alpha=154, \sigma_{\max }=186 \mathrm{~m}\right.$ and $\left.\sigma_{\min }=42 \mathrm{~m}\right)$. The estimates of $\delta$ obtained under the assumption of isotropic dispersal and with density set at its observed value exhibited negative bias for all sample sizes. This bias was constant with increasing $n_{\mathrm{p}}$, but increased with increasing $n_{\mathrm{m}}$, whereas the standard deviation decreased with both $n_{\mathrm{p}}$ and $n_{\mathrm{m}}$, yielding an overall increase of the $\sqrt{\mathrm{MSE}}$. When density was jointly estimated, the procedure yielded an upward bias for $\hat{d}_{\mathrm{e}}$, except for the largest sampling effort $\left(n_{\mathrm{m}}=62\right.$ and $\left.n_{\mathrm{p}}=40\right)$. The dispersal distance $(\hat{\delta})$ jointly estimated with $\hat{d}_{\mathrm{e}}$ showed a negative bias and a larger $\sqrt{\text { MSE }}$ than when density was fixed. This $\sqrt{\text { MSE }}$ decreased when $n_{\mathrm{m}}$ or $n_{\mathrm{p}}$ increased, with $n_{\mathrm{p}}$ having the stronger impact. It reached a reasonable value $(30 \%)$ only for the largest sampling effort.

Consider now the estimates obtained under the correct assumption of anisotropic dispersal, with density set at its observed value. The main dispersal angle $(\alpha)$ was always correctly estimated with minimal bias and MSE, and increasing either the number of mothers $\left(n_{\mathrm{m}}\right)$ or the progeny size $\left(n_{\mathrm{p}}\right)$ had little effect. The estimated 
Table 1 Bias, standard deviation and root mean-squared error $(\sqrt{\mathrm{MSE}})$ of the various estimates of the dispersal parameters for four combination of the number of mothers $\left(n_{\mathrm{m}}\right)$ and the progeny size $\left(n_{\mathrm{p}}\right)$ based on field study estimates

\begin{tabular}{|c|c|c|c|c|c|c|c|c|c|c|c|c|}
\hline \multirow[t]{2}{*}{$\mathrm{n}_{m}-\mathrm{n}_{p}{ }^{\mathrm{a}}$} & \multicolumn{3}{|c|}{ Isotropic dispersal assumed } & \multicolumn{9}{|c|}{ Anisotropic dispersal assumed } \\
\hline & $\delta^{\mathrm{b}}(\%)$ & $\mathrm{d}^{\mathrm{c}}(\%)$ & $\delta^{\mathrm{d}}(\%)$ & $\sigma_{\max }^{\mathrm{e}}(\%)$ & $\sigma_{\min }{ }^{\mathrm{e}}(\%)$ & $\alpha^{\mathrm{e}}$ & $\delta^{\mathrm{e}}(\%)$ & $\mathrm{d}^{\mathrm{f}}(\%)$ & $\sigma_{\max }^{\mathrm{g}}(\%)$ & $\sigma_{\min }^{\mathrm{g}}(\%)$ & $\alpha^{\mathrm{g}}(\%)$ & $\delta^{\mathrm{g}}$ \\
\hline \multicolumn{13}{|l|}{$31-20$} \\
\hline Bias & -0.7 & 67.5 & -21.2 & 67.4 & 23.6 & 0.60 & 71.5 & -14.6 & 74.2 & 22.5 & -0.71 & 78.1 \\
\hline s.d. & 7.4 & 140.5 & 29.2 & 54.5 & 33.9 & 12.87 & 50.8 & 49.7 & 112.8 & 43.0 & 11.31 & 109.8 \\
\hline$\sqrt{\mathrm{MSE}}$ & 7.4 & 155.9 & 36.1 & 86.6 & 41.4 & 12.88 & 87.7 & 51.9 & 135.1 & 48.6 & 11.33 & 134.7 \\
\hline \multicolumn{13}{|l|}{$31-40$} \\
\hline Bias & 0.1 & 23.9 & -18.8 & 42.2 & 40.5 & 1.54 & 48.5 & -7.4 & 23.3 & 28.8 & 0.02 & 29.3 \\
\hline s.d. & 4.4 & 57.1 & 17.7 & 25.4 & 21.1 & 7.03 & 22.8 & 27.3 & 24.7 & 23.4 & 4.81 & 23.9 \\
\hline$\sqrt{\mathrm{MSE}}$ & 4.4 & 61.9 & 25.8 & 49.3 & 45.7 & 7.20 & 53.6 & 28.3 & 33.9 & 37.1 & 4.81 & 37.9 \\
\hline \multicolumn{13}{|l|}{$62-20$} \\
\hline Bias & -7.3 & 40.2 & -28.9 & 35.3 & 32.6 & 3.10 & 41.5 & -17.2 & 32.8 & 31.6 & 1.71 & 39.0 \\
\hline s.d. & 4.6 & 78.7 & 14.9 & 29.0 & 29.2 & 11.28 & 25.2 & 38.2 & 77.2 & 36.8 & 9.40 & 75.4 \\
\hline$\sqrt{\mathrm{MSE}}$ & 8.6 & 88.4 & 32.5 & 45.7 & 43.8 & 11.70 & 48.5 & 42.0 & 83.9 & 48.5 & 9.56 & 84.9 \\
\hline \multicolumn{13}{|l|}{$62-40$} \\
\hline Bias & -7.9 & -4.1 & -19.0 & 16.2 & 49.5 & 6.01 & 25.0 & -29.6 & 18.1 & 56.8 & 6.35 & 27.6 \\
\hline s.d. & 2.8 & 29.0 & 10.7 & 16.1 & 24.1 & 7.87 & 12.3 & 26.3 & 22.0 & 39.9 & 8.44 & 22.1 \\
\hline$\sqrt{\mathrm{MSE}}$ & 8.4 & 29.3 & 21.8 & 22.8 & 55.1 & 9.90 & 27.9 & 39.5 & 28.5 & 69.4 & 10.56 & 35.3 \\
\hline
\end{tabular}

Abbreviation: s.d., standard deviation.

The pollen dispersal function used is the anisotropic bivariate normal distribution, as defined in Equation (1), with parameters $\alpha=154^{\circ}$, $\sigma_{\max }=186 \mathrm{~m}$ and $\sigma_{\min }=42 \mathrm{~m}$, and $\delta=151 \mathrm{~m}$.

aprogeny size.

${ }^{\mathrm{b}}$ Pairwise estimate of dispersal distance (isotropy assumed and fixed density) in meters.

${ }^{\mathrm{c}}$ Density estimated jointly.

${ }^{\mathrm{d}}$ Pairwise estimate of dispersal distance (isotropy assumed and jointly estimated density) in meters.

eEstimated with fixed density.

fointly estimated density.

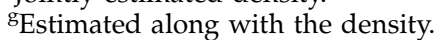

dispersal along the main axis $\left(\hat{\sigma}_{\text {max }}\right)$ showed high upward bias $(\sim 67 \%)$ and $\sqrt{\mathrm{MSE}}(\sim 87 \%)$ for the lowest sample size. Bias and $\sqrt{\mathrm{MSE}}$ decreased with the sample size, the decrease being slightly higher when $n_{\mathrm{m}}$ was doubled than when $n_{\mathrm{p}}$ was doubled. The dispersal along the orthogonal axis $\left(\hat{\sigma}_{\min }\right)$ showed lower relative bias and $\sqrt{\text { MSE }}$ than $\hat{\sigma}_{\max }$ for the lowest sample sizes. However, while these bias and $\sqrt{\text { MSE }}$ decreased with increasing $n_{\mathrm{p}}$ as expected, this was not the case with increasing $n_{\mathrm{m}}$, where it remained either constant or even increased. Thus, the relative bias was higher for $\hat{\sigma}_{\text {min }}$ than for $\hat{\sigma}_{\max }$ for the highest values of $n_{\mathrm{m}}$ and $n_{\mathrm{p}}$. As a whole, the $\sqrt{\mathrm{MSE}}$ of the estimate of dispersal distance $(\hat{\delta})$ always decreased with increasing sample size, the effect being slightly stronger for a doubled $n_{\mathrm{m}}$ than for a doubled $n_{\mathrm{p}}$, as for $\hat{\sigma}_{\text {max }}$. The unexpected behaviour of $\hat{\sigma}_{\text {min }}$ might be a consequence of a trade-off, the increase of the precision of $\hat{\sigma}_{\text {max }}$ and $\hat{\delta}$ being obtained in some cases at the cost of a small loss of precision for $\hat{\sigma}_{\text {min }}$.

When density was estimated jointly with the dispersal parameters, the estimates of these dispersal parameters $\left(\hat{\sigma}_{\max }, \hat{\sigma}_{\min }\right.$ and $\left.\hat{\alpha}\right)$, and thus of average dispersal distance $(\hat{\delta})$, showed approximately twice as much bias and $\sqrt{\mathrm{MSE}}$ as for the case where density was fixed. The impact of an increasing $n_{\mathrm{m}}$ and/or $n_{\mathrm{p}}$ was the same as above. Regarding the estimated density $\left(\hat{d}_{\mathrm{e}}\right)$, it showed quite a large $\sqrt{\operatorname{MSE}}(\sim 52 \%)$ for the minimal values of $n_{\mathrm{m}}$ and $n_{\mathrm{p}}$, but much less than when isotropic dispersal was assumed for the estimation. This high $\sqrt{\mathrm{MSE}}$ of $\hat{d}_{\mathrm{e}}$ decreased strongly with an increase of $n_{p}$, but not so much with an increase of $n_{\mathrm{m}}$.
The simulations performed with an anisotropic dispersal distribution, with the same $\sigma_{\max }$ and $\sigma_{\min }$ as before, but with a $\alpha$ parameter of $64^{\circ}$, showed similar results (Table 2), the biases and $\sqrt{\text { MSE }}$ being higher in some cases but lower in others.

For simulations performed with isotropic dispersal (Table 3), isotropic estimates behaved as expected. We observed a decrease of bias and $\sqrt{\mathrm{MSE}}$ with increasing $n_{\mathrm{m}}$ or $n_{\mathrm{p}}$. When anisotropic dispersal was assumed for estimation, so that we might anticipate dissimilar estimates of $\sigma_{\max }$ and $\sigma_{\min }$, there was an upward bias for $\sigma_{\max }$ and thus for $\delta$, but bias decreases with increasing progeny sample size; $\sigma_{\min }$ showed only limited bias. When density was fixed, the decrease in bias and $\sqrt{\mathrm{MSE}}$ was stronger for an increase of $n_{\mathrm{p}}$ than for an increase of $n_{\mathrm{m}}$, whereas the opposite pattern occurred when density was jointly estimated. As expected, the estimate of $\alpha$ showed considerable variance, which does not decrease with sample size, since there is no particular value of $\alpha$ that is true in the isotropic case.

\section{Power of the method}

Considering first the simulations where dispersal was truly anisotropic $\left(\alpha=154^{\circ}\right.$ or $64^{\circ}, \sigma_{\max }=186 \mathrm{~m}$ and $\sigma_{\min }=42 \mathrm{~m}$ ), we observed an increased probability of detecting anisotropy at the $5 \%$ or the $1 \%$ level with either increasing $n_{\mathrm{m}}$ or $n_{\mathrm{p}}$ (Table 4). For the minimal sample size $\left(n_{\mathrm{m}}=31\right.$ and $\left.n_{\mathrm{p}}=20\right)$, the probability of detecting anisotropy was low for both values of $\alpha$, whether density 
Table 2 Bias, standard deviation and root mean squared error $(\sqrt{\mathrm{MSE}})$ of the various estimates of the dispersal parameters for four combination of the number of mothers $\left(n_{\mathrm{m}}\right)$ and the progeny size $\left(n_{\mathrm{p}}\right)$ with $\alpha=64^{\circ}$

\begin{tabular}{|c|c|c|c|c|c|c|c|c|c|c|c|c|}
\hline \multirow[t]{2}{*}{$\mathrm{n}_{m}-\mathrm{n}_{p}{ }^{\mathrm{a}}$} & \multicolumn{3}{|c|}{ Isotropic dispersal assumed } & \multicolumn{9}{|c|}{ Anisotropic dispersal assumed } \\
\hline & $\delta^{\mathrm{b}}(\%)$ & $\mathrm{d}^{\mathrm{c}}(\%)$ & $\delta^{\mathrm{d}}(\%)$ & $\sigma_{\max } \mathrm{e}(\%)$ & $\sigma_{\min }{ }^{\mathrm{e}}(\%)$ & $\alpha^{\mathrm{e}}$ & $\delta^{\mathrm{e}}(\%)$ & $\mathrm{d}^{\mathrm{f}}(\%)$ & $\sigma_{\max }^{\mathrm{g}}(\%)$ & $\sigma_{\min }{ }^{\mathrm{g}}(\%)$ & $\alpha^{\mathrm{g}}$ & $\delta^{\mathrm{g}}(\%)$ \\
\hline \multicolumn{13}{|l|}{$31-20$} \\
\hline Bias & -9.4 & 140.7 & -38.5 & 67.1 & 13.4 & 2.40 & 70.6 & -24.2 & 143.1 & 23.6 & 3.66 & 145.8 \\
\hline s.d. & 5.8 & 169.3 & 39.1 & 51.4 & 36.5 & 12.83 & 46.7 & 51.6 & 217.0 & 77.9 & 15.49 & 211.7 \\
\hline$\sqrt{\mathrm{MSE}}$ & 11.0 & 220.2 & 54.8 & 84.5 & 38.9 & 13.05 & 84.6 & 57.0 & 260.0 & 81.4 & 15.91 & 257.0 \\
\hline \multicolumn{13}{|l|}{$31-40$} \\
\hline Bias & -8.6 & 184.6 & -51.1 & 86.6 & -2.9 & 3.58 & 87.5 & -31.3 & 151.4 & -2.3 & 3.68 & 151.0 \\
\hline s.d. & 3.6 & 106.1 & 9.3 & 28.4 & 15.0 & 3.39 & 26.6 & 35.0 & 164.5 & 15.5 & 3.52 & 160.4 \\
\hline$\sqrt{\mathrm{MSE}}$ & 9.3 & 212.9 & 51.9 & 91.2 & 15.3 & 4.93 & 91.4 & 47.0 & 223.6 & 15.7 & 5.09 & 220.3 \\
\hline \multicolumn{13}{|l|}{$62-20$} \\
\hline Bias & -13.5 & -39.9 & 2.7 & 13.6 & 34.8 & 8.14 & 20.9 & -51.1 & 62.0 & 66.3 & 1.88 & 70.0 \\
\hline s.d. & 4.2 & 49.9 & 23.8 & 19.4 & 18.1 & 4.62 & 17.1 & 23.6 & 80.5 & 69.3 & 16.46 & 80.2 \\
\hline$\sqrt{\mathrm{MSE}}$ & 14.1 & 63.9 & 23.9 & 23.7 & 39.3 & 9.36 & 27.0 & 56.3 & 101.6 & 95.9 & 16.57 & 106.5 \\
\hline \multicolumn{13}{|l|}{$62-40$} \\
\hline Bias & -13.5 & 32.9 & -32.3 & 34.4 & 15.3 & 2.49 & 38.7 & -19.8 & 18.5 & 15.6 & 3.32 & 23.5 \\
\hline s.d. & 2.8 & 62.6 & 13.7 & 21.6 & 14.3 & 3.86 & 19.6 & 20.2 & 19.0 & 15.3 & 3.48 & 18.4 \\
\hline$\sqrt{\mathrm{MSE}}$ & 13.7 & 70.7 & 35.1 & 40.7 & 21.0 & 4.59 & 43.4 & 28.3 & 26.5 & 21.9 & 4.81 & 29.8 \\
\hline
\end{tabular}

Abbreviation: s.d., standard deviation.

The pollen dispersal function used is the anisotropic bivariate normal distribution, as defined in Equation (1), with parameters $\alpha=64^{\circ}$, $\sigma_{\max }=186 \mathrm{~m}$ and $\sigma_{\min }=42 \mathrm{~m}$, and $\delta=151 \mathrm{~m}$ (same as the estimated values, except that the orientation is perpendicular).

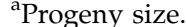

${ }^{\mathrm{b}}$ Pairwise estimate of dispersal distance (isotropy assumed and fixed density).

${ }^{\mathrm{c}}$ Density estimated jointly.

${ }^{\mathrm{d}}$ Pairwise estimate of dispersal distance (isotropy assumed and jointly estimated density).

${ }^{\mathrm{e}}$ Estimated with fixed density.

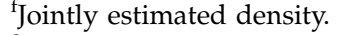

${ }^{\mathrm{g}}$ Estimated along with the density.

Table 3 Bias, standard deviation and root mean squared error $(\sqrt{\mathrm{MSE}})$ of the various estimates of the dispersal parameters for four combination of the number of mothers $\left(n_{\mathrm{m}}\right)$ and the progeny size $\left(n_{\mathrm{p}}\right)$ for isotropic dispersal

\begin{tabular}{|c|c|c|c|c|c|c|c|c|c|c|c|c|}
\hline \multirow[t]{2}{*}{$\mathrm{n}_{m}-\mathrm{n}_{p}{ }^{\mathrm{a}}$} & \multicolumn{3}{|c|}{ Isotropic dispersal assumed } & \multicolumn{9}{|c|}{ Anisotropic dispersal assumed } \\
\hline & $\delta^{\mathrm{b}}(\%)$ & $\mathrm{d}^{\mathrm{c}}(\%)$ & $\delta^{\mathrm{d}}(\%)$ & $\sigma_{\max }^{\mathrm{e}}(\%)$ & $\sigma_{\min }{ }^{\mathrm{e}}(\%)$ & $\alpha^{e}$ & $\delta^{\mathrm{e}}(\%)$ & $d^{f}(\%)$ & $\sigma_{\max }^{\mathrm{g}}(\%)$ & $\sigma_{\min }^{\mathrm{g}}(\%)$ & $\alpha^{\mathrm{g}}$ & $\delta^{\mathrm{g}}(\%)$ \\
\hline \multicolumn{13}{|l|}{$31-20$} \\
\hline Bias & 29.9 & -11.8 & 58.4 & 135.4 & -19.1 & $\mathrm{NA}^{\mathrm{h}}$ & 76.6 & -46.1 & 410.0 & 11.7 & $\mathrm{NA}^{\mathrm{h}}$ & 262.7 \\
\hline s.d. & 14.8 & 106.2 & 83.0 & 124.5 & 24.5 & 44.40 & 75.6 & 65.9 & 581.5 & 63.6 & 46.91 & 380.8 \\
\hline$\sqrt{\mathrm{MSE}}$ & 33.3 & 106.9 & 101.5 & 183.9 & 31.1 & $\mathrm{NA}^{\mathrm{h}}$ & 107.6 & 80.4 & 711.5 & 64.6 & $\mathrm{NA}^{\mathrm{h}}$ & 462.6 \\
\hline \multicolumn{13}{|l|}{$31-40$} \\
\hline Bias & 23.8 & -20.2 & 29.8 & 81.6 & -12.3 & $N A^{h}$ & 45.1 & -27.7 & 101.7 & -4.6 & $\mathrm{NA}^{\mathrm{h}}$ & 60.5 \\
\hline s.d. & 7.4 & 44.6 & 42.3 & 50.1 & 17.6 & 43.49 & 26.9 & 46.8 & 105.8 & 28.5 & 38.75 & 69.6 \\
\hline$\sqrt{\mathrm{MSE}}$ & 24.9 & 49.0 & 51.8 & 95.7 & 21.4 & NA & 52.5 & 54.4 & 146.8 & 28.9 & $\mathrm{NA}^{\mathrm{h}}$ & 92.2 \\
\hline \multicolumn{13}{|l|}{$62-20$} \\
\hline Bias & 3.4 & 6.3 & 15.4 & 52.7 & -24.8 & $N A^{h}$ & 18.6 & -13.0 & 106.0 & -12.6 & $\mathrm{NA}^{\mathrm{h}}$ & 54.3 \\
\hline s.d. & 7.8 & 89.7 & 39.2 & 57.3 & 17.0 & 49.4 & 31.3 & 68.0 & 128.0 & 30.2 & 50.0 & 81.2 \\
\hline$\sqrt{\mathrm{MSE}}$ & 8.5 & 89.9 & 42.1 & 77.9 & 30.1 & $\mathrm{NA}^{\mathrm{h}}$ & 36.4 & 69.2 & 166.2 & 32.8 & $\mathrm{NA}^{\mathrm{h}}$ & 97.7 \\
\hline \multicolumn{13}{|l|}{$62-40$} \\
\hline Bias & 14.6 & -4.8 & 2.4 & 49.0 & -9.3 & $\mathrm{NA}^{\mathrm{h}}$ & 26.7 & -21.1 & 49.0 & -11.7 & $\mathrm{NA}^{\mathrm{h}}$ & 25.6 \\
\hline s.d. & 4.5 & 35.7 & 16.0 & 36.2 & 11.9 & 36.54 & 20.2 & 35.2 & 40.5 & 15.3 & 39.53 & 27.0 \\
\hline$\sqrt{\mathrm{MSE}}$ & 15.3 & 36.1 & 16.2 & 60.9 & 15.1 & $\mathrm{NA}^{\mathrm{h}}$ & 33.5 & 41.1 & 63.6 & 19.3 & $\mathrm{NA}^{\mathrm{h}}$ & 37.2 \\
\hline
\end{tabular}

Abbreviations: NA, not applicable; s.d., standard deviation.

The true dispersal function is the isotropic bivariate normal distribution, with $\sigma=125 \mathrm{~m}, \delta=177 \mathrm{~m}$.

aProgeny size.

${ }^{\mathrm{b}}$ Pairwise estimate of dispersal distance (isotropy assumed and fixed density).

${ }^{\mathrm{c}}$ Density estimated jointly.

${ }^{\mathrm{d}}$ Pairwise estimate of dispersal distance (isotropy assumed and jointly estimated density).

estimated with fixed density.

fJointly estimated density.

${ }^{\mathrm{g}}$ Estimated along with the density.

${ }^{\mathrm{h}}$ No bias and MSE could be computed here for a since the true dispersal function is isotropic and has thus no value for $\alpha$. 
Table 4 Proportion of cases where anisotropy is detected at the $5 \%$ level $(P<0.05)$ or the $1 \%$ level $(P<0.01)$ in the simulated data sets for the three assumed dispersal functions and four combination of the number of mothers $\left(n_{\mathrm{m}}\right)$ and the progeny size $\left(n_{\mathrm{p}}\right)$, when density is either set at its known value or jointly estimated with the dispersal parameters

\begin{tabular}{|c|c|c|c|c|c|}
\hline \multirow[t]{2}{*}{ Dispersal distribution } & \multirow[t]{2}{*}{$\mathrm{n}_{m}-\mathrm{n}_{p}$} & \multicolumn{2}{|c|}{ Fixed density } & \multicolumn{2}{|c|}{ Density jointly estimated } \\
\hline & & $\mathrm{P}<0.05(\%)$ & $\mathrm{P}<0.01(\%)$ & $\mathrm{P}<0.05(\%)$ & $\mathrm{P}<0.01(\%)$ \\
\hline \multirow{4}{*}{$\begin{array}{l}\text { Anisotropy } \\
\text { with }\left(\alpha=154^{\circ}\right)\end{array}$} & $31-20$ & 11.40 & 1.10 & 11.60 & 2.90 \\
\hline & $31-40$ & 60.85 & 9.84 & 37.81 & 2.68 \\
\hline & $62-20$ & 14.81 & 0.00 & 65.84 & 34.98 \\
\hline & $62-40$ & 84.40 & 47.71 & 85.32 & 44.04 \\
\hline & $31-20$ & 26.70 & 1.30 & 25.50 & 11.30 \\
\hline \multirow[t]{3}{*}{ with $\left(\alpha=64^{\circ}\right)$} & $31-40$ & 98.24 & 84.00 & 44.96 & 27.84 \\
\hline & $62-20$ & 22.81 & 0.92 & 26.73 & 12.44 \\
\hline & $62-40$ & 100.00 & 29.94 & 98.80 & 77.25 \\
\hline Isotropic & $31-20$ & 2.50 & 0.40 & 7.80 & 1.30 \\
\hline \multirow[t]{3}{*}{ dispersal } & $31-40$ & 4.84 & 1.54 & 2.42 & 0.88 \\
\hline & $62-20$ & 3.91 & 0.78 & 13.28 & 7.81 \\
\hline & $62-40$ & 4.84 & 1.54 & 2.42 & 0.88 \\
\hline
\end{tabular}

was fixed or jointly estimated. An increase of $n_{\mathrm{p}}$ yielded generally a higher increase of the probability of detecting anisotropy than an increase of $n_{\mathrm{m}}$. To detect anisotropy when density was jointly estimated required substantial amounts of data, it could only be detected in about half of the cases when $n_{\mathrm{p}}$ was doubled, and it was only for the maximal sample size $\left(n_{\mathrm{m}}=62\right.$ and $\left.n_{\mathrm{p}}=40\right)$ that it could be detected in a large majority of cases. Considering simulations with isotropic dispersal, spurious anisotropy was usually detected in a proportion close to the expected $5 \%$ or $1 \%$ level, for all values of $n_{\mathrm{m}}$ and $n_{\mathrm{p}}$.

\section{Discussion}

\section{Anisotropy in Valley oak pollen flow}

We find only a slight tendency towards anisotropy of pollen dispersal here, despite a strong prevailing wind direction for the region. Our estimates were nonsignificant, which is consistent with our simulation study, showing that it is quite difficult to detect anisotropy with progeny sizes of less than 20 offspring per mother. Also consistent with the simulation study, we found that the standard deviations of the estimates were low for $\alpha$ and $\sigma_{\min }$, but much higher for $\sigma_{\max }$. The inferred main direction estimated either with fixed density $\left(\hat{\alpha}=154^{\circ}\right.$, s.d. $\left.=2.63^{\circ}\right)$ or with density jointly estimated $\left(\hat{\alpha}=152\right.$, s.d. $\left.=7.22^{\circ}\right)$, was not coincident with the main wind direction $\left(112^{\circ}\right)$. This discrepancy suggests that pollen movement may be influenced by very localized wind patterns. On the basis of the results of our simulation study, it does not seem that the angle we detected is a consequence of the specific spatial arrangement of trees. However, if the orientation of the valley modifies the local directionality of wind and if the spatial heterogeneity of trees modifies the aerodynamics of pollen movement, the angle $\alpha$ may not conform to the prevailing regional wind direction. In the case of Valley oak, we will need a larger data set to assess the angle and standard deviation of the directionality of the pollen flow. Increasing the number of mothers, in particular, will probably reduce the impact of the local effects, providing a more general trend.
As a comparison, we also evaluated anisotropy in our study population with the NEIGHBOR method of Burczyk et al. (1996). This method also failed to detect a significant level of anisotropic dispersal, and the non-significant tendency $\left(60^{\circ}\right.$ from the North axis) was also quite different from the main wind direction, again highlighting a need for more data. With either analysis, however, the signal is weak and non-significant, and neither approach indicates that pollen movement is strongly directional in this population of valley oak.

One motivation for this study was to test whether the subtle (and non-significant) anisotropy identified in the adult population of Valley oak (Dutech et al., 2005) was consistent with anisotropy in the progeny population. For adult genotypes, the major axis of orientation was $\alpha$ $=106.5^{\circ}$, about $6^{\circ}-7^{\circ}$ 'off the wind.' In that study, we speculated that the anisotropic signal was weakened as the seedling populations aged into adult populations. However, we now observe for the progenies that the pollen orientation is even further 'off the wind.' This discrepancy might be the consequence of the imprecision induced by the limited sample sizes of both the adult and the offspring studies. Alternatively it could be caused by specific events that have occurred during the single year of study. Again it would be helpful to conduct a comparative study over several years, using the same mother trees and the same molecular markers, such as that performed by Irwin et al. (2003) for Albizia julibrissin or that for Sorbus torminalis by Oddou-Muratorio et al. (2005). Unfortunately, it is quite unusual for the same set of $Q$. lobata trees to produce acorns in consecutive years owing to the masting dynamics of most oaks (for example, Nakanishi et al., 2005), so such replications would require a long-term study.

For the moment, we can only compare our study with the previous study of pollen dispersal performed in this same population (Sork et al., 2002). Assuming a normal dispersal distribution and effective density based on the natural population, the estimated value of $\delta$ in this previous study was of $65 \mathrm{~m}$. Here, assuming a fixed density as in this previous study, the Gaussian dispersal mean value of $\delta=110 \mathrm{~m}$, which is a bit higher than observed in 1999 but the same order of magnitude. This 
limited difference between 1999 and 2001 might be due either to differences in sampling (more individuals in the centre of the population for 2001 sampling) or to differences in intensity of pollination between the 2 years. On the basis of these 2 years, we conclude so far that it does not appear that directional pollen flow is biasing our estimates of pollen flow.

\section{Detecting anisotropy and estimating its level}

Our simulation study illustrates both the possibility and the difficulty of demonstrating anisotropic pollen dispersal. It is possible to detect such anisotropy in pollen dispersal if it exists, using just the genotypic data on seed trees and their offspring, by way of TWOGENER extraction. The bias and $\sqrt{\mathrm{MSE}}$ for the dispersal parameters $\left(\sigma_{\max }, \sigma_{\min }\right.$ and $\alpha$ ) are quite high with low numbers of offspring per mother, but they decrease readily when this number increases. $\sigma_{\max }$ has higher bias and $\sqrt{\mathrm{MSE}}$ than $\alpha$ and $\sigma_{\min }$ for low sample sizes, which means that more data are needed to estimate that parameter well. Our simulations show also that using the isotropic estimates while the true dispersal is anisotropic yields a systematic underestimation of mean dispersal distance of pollen $(\delta)$.

Regarding the impact of the shape of the population, it is interesting to note that in terms of bias and $\sqrt{\mathrm{MSE}}$, and in terms of the power to detect anisotropy, our estimates performed about equally well with a major axis of pollen dispersal that parallels the main axis of distribution for the population (along Figueroa Creek) or orthogonal to it (across the Valley). So, we can conclude that this method is reasonably robust in detecting a predominant direction of pollination, even if the adult trees are preferentially distributed along a divergent axis. Moreover, our method is unlikely to detect excessive and spurious anisotropy when the true dispersal curve is isotropic. Because the percentage of these cases of spurious anisotropy detected $(\sim 10 \%)$ is a bit higher than the $5 \%$ expected by chance, an anisotropic signal that would just be detected at or close to the $5 \%$ level should be considered with caution.

The progeny sample size needed to provide sufficient power depends on the strength of anisotropy, the degree of polymorphism of the genetic markers and the array of spatial positions occupied by the mothers, but if only $\sim 30$ mothers are considered, at least 40 offspring each will be necessary to have a reasonable chance of detecting anisotropy (see Table 4). Unlike the situation for isotropic dispersal (Austerlitz and Smouse, 2002), increasing the number of mothers is, in most cases, less efficient than increasing the number of offspring. This may stem from the fact that, with a limited number of offspring, the $\phi_{i j}$ values may, by chance, be elevated in one particular direction, yielding spurious anisotropy in the simulations performed under the isotropic model to obtain the null distribution, thus reducing the power to detect this anisotropy. Additional simulations will be needed to explore the sampling aspects more thoroughly.

Sample sizes for anisotropic analyses should be very large if the effective density is jointly estimated. The simulations performed here demonstrated that it is preferable for the investigator to provide some independent estimate of effective density, because it is much easier - especially for low sample sizes - to detect anisotropy when effective density is fixed. The trouble is that this estimate might be difficult to obtain, since many factors, such as spatial aggregation of the adults, phenological differences and differences in male fertility (see Meagher and Vassiliadis, 2003; Oddou-Muratorio et al., 2005), will affect the ratio of effective to observed density. Some effort to gain more information on these other factors would be quite valuable. Alternatively, it is possible to use the observed density or the density estimated under the isotropic model, with the caveat that the detection of the angle will have more power, but dispersal distance may be underestimated.

Another important issue concerns the family of dispersal curve assumed. Here, we assumed a bivariate normal pollen dispersal distribution for the sake of mathematical tractability. We have shown elsewhere that fat-tailed curves are more realistic in natural populations (Austerlitz et al., 2004). No closed-form analytical formulae are available for the $\phi_{i j}$ for such curves, so while the results can be computed numerically, the methods are elaborate and computer-intensive, due to the number of parameters to be estimated for the anisotropic case (four or five, depending on whether density is or is not estimated jointly). Such methods will need further development in future work. Since our prime interest here is in detecting anisotropy, assuming that dispersal is normal might not be a bad place to start.

This extension of the TWOGENER modelling approach provides a promising avenue for the estimation of the degree of anisotropy in plant populations where directionality of pollen movement is a concern. This method differs substantially from the Neighborhood model that includes distance and directionality in modelling pollen flow (for example, Burczyk et al., 1996). The Neighborhood model essentially uses a parentage approach to identify pollen donors, and like all parentage approaches, relies on access to the genotypes of all potential pollen donors within a proscribed area around focal seed parents (Smouse and Sork, 2004). The Neighborhood model provides an estimate of the angle of directionality of pollen movement from pollen source to pollen recipient, whereas this TwoGener treatment provides the angle, but without respect to directionality, so treatment of the angular displacement is antisymmetric. Another difference in the two methods is that Neighbourhood model uses likelihood ratio criteria, which can be tested either with a $\chi^{2}$ approximation or a permutational procedure. The choice of methods must depend on the sampling design and the availability of paternal genotypes.

In conclusion, we have shown here that it is clearly feasible (with appropriate experimental designs) to detect anisotropy in pollen dispersal in natural populations, using a TWOGENER extraction. Our simulations indicate the need for greater replication, both within and among mothers, than provided with this particular data set. Our main objective here was to introduce a formal methodology. We have begun, with some limited simulations, to provide some hints concerning better sampling strategies, but this matter should be the subject of a specific study in the future. Detecting anisotropy is, in any case, a matter of some importance. Indeed, we show here that neglecting anisotropy yields an underestimate of the mean dispersal distance and an even greater underestimate of dispersal distance along the main axis. 


\section{Acknowledgements}

We thank the managing editor (Professor RA Nichol), the editor and three anonymous referees for helpful comments and suggestions on the first version of the manuscript. We also thank J Burczyk for providing us his NEIGHBOR program and Delphine Grivet for help with the laboratory analysis in later stages. VLS and CD received support from NSF-DEB-0089445 and NSF-DEB0242422; PES was supported by USDA/NJAES 171131, NSF-DEB-0089238 and NSF-DEB-0514956, and FWD received support from NSF-DEB-0089495. Some of the simulations were performed on the UNIX machines of the Université de Paris-Sud and on the cluster of the Muséum National d'Histoire Naturelle, partially financed by the GDR 'Génomique des Populations'.

\section{References}

Adams WT, Birkes DS (1991). Estimating mating patterns in forest tree populations. In: Fineschi S, Malvolti ME, Cannata F, Hattemer HH (eds). Biochemical Markers in the Population Genetics of Forest Trees. SPB Academic Publishing: Hague, the Netherlands. pp 152-172.

Adams WT, Griffin AR, Moran GF (1992). Using paternity analysis to measure effective pollen dispersal in plant populations. Am Nat 140: 762-780.

Austerlitz F, Dick CW, Dutech C, Klein EK, Oddou-Muratorio S, Smouse PE et al. (2004). Using genetic markers to estimate the pollen dispersal curve. Mol Ecol 13: 937-954.

Austerlitz F, Smouse PE (2001). Two-generation analysis of pollen flow across a landscape. II. Relation between $\Phi_{\mathrm{ft}}$, pollen dispersal and inter-females distance. Genetics 157: 851-857.

Austerlitz F, Smouse PE (2002). Two-generation analysis of pollen flow across a landscape. IV. Estimating the dispersal parameter. Genetics 161: 355-363.

Bateman AJ (1947). Contamination of seed crops II. Wind pollination. Heredity 1: 235-246.

Burczyk J, Adams WT, Moran GF, Griffin AR (2002). Complex patterns of mating revealed in a Eucalyptus regnans seed orchard using allozyme markers and the neighbourhood model. Mol Ecol 11: 2379-2391.

Burczyk J, Adams W, Shimizu J (1996). Mating patterns and pollen dispersal in a natural knobcone pine (Pinus attenuata Lemmon) stand. Heredity 77: 251-260.

Burczyk J, Koralewski JE (2005). Parentage versus two-generation analyses for estimating pollen-mediated gene flow in plant populations. Mol Ecol 14: 2525-2537.

Burczyk J, Lewandowski A, Chalupka W (2004). Local pollen dispersal and distant gene flow in Norway spruce (Picea abies L. Karst.). Forest Ecol Manage 197: 39-48.

Burczyk J, Prat D (1997). Male reproductive success in Pseudotsuga menziesii (Mirb.) France: the effects of spatial structure and flowering characteristics. Heredity 79: 638-647.

Couvet D (2002). Deleterious effects of restricted gene flow in fragmented populations. Cons Biol 16: 369-376.

Dow BD, Ashley MV, Howe HF (1995). Characterization of highly variable $(\mathrm{GA} / \mathrm{CT})(\mathrm{n})$ microsatellites in the bur oak, Quercus macrocarpa. Theor Appl Genet 91: 137-141.

Dutech C, Sork VL, Irwin AJ, Smouse PE, Davis FW (2005). Gene flow and fine-scale genetic structure in a windpollinated tree species Quercus lobata (Fagaceaee). Amer J Botany 92: 252-261.

Fernández-M JF, Sork VL (2007). Genetic variation in fragmented forest stands of the Andean Oak Quercus humboldtii Bonpl. (Fagaceae). Biotropica 39: 72-78.
Irwin AJ, Hamrick JL, Godt MJW, Smouse PE (2003). A multiyear estimate of the effective pollen donor pool for Albizia julibrissin. Heredity 90: 187-194.

Klein EK, Lavigne C, Picault H, Renard M, Gouyon P-H (2006). Pollen dispersal of oilseed rape: estimation of the dispersal function and effects of field dimension. J Appl Ecol 43: 141-151.

Ledig FT (1992). Human impacts on genetic diversity in forest ecosystems. Oikos 63: 87-108.

Lian C, Miwa M, Hogetsu T (2001). Outcrossing and paternity analysis of Pinus densiflora (Japanese red pine) by microsatellite polymorphism. Heredity 87: 88-98.

Lowe AJ, Boshier D, Ward M, Bacles CFE, Navarro C (2005). Genetic resource impacts of habitat loss and degradation; reconciling empirical evidence and predicted theory for neotropical trees. Heredity 95: 255-273.

Meagher TR, Belanger FC, Day PR (2003). Using empirical data to model transgene dispersal. Philos Trans Royal Soc London B 358: 1157-1162.

Meagher TR, Vassiliadis C (2003). Spatial geometry determines gene flow in plant populations. In: Hails RS, Beringer JE, Godfray HCJ (eds). Genes in the Environment. Blackwell Publishing: Oxford. pp 76-90.

Nason JD, Aldrich PR, Hamrick JL (1997). Dispersal and the dynamics of genetic structure in fragmented tropical tree populations. In: Laurance WF, Bierregaard Jr RO (eds). Tropical Forest Remnants: Ecology, Management, and Conservation of Fragmented Communities. University of Chicago Press: Chicago. pp 304-320.

Nakanishi A, Tomaru N, Yoshimaru H, Manabe T, Yamamoto S (2005). Interannual genetic heterogeneity of pollen pools accepted by Quercus salicina individuals. Mol Ecol 14: 4469-4478.

Nichols RA, Hewitt GM (1994). The genetic consequences of long distance dispersal during colonization. Heredity 72: 312-317.

Oddou-Muratorio S, Klein EK, Austerlitz F (2005). Real-time patterns of pollen flow in the wildservice tree, Sorbus torminalis (L.) Crantz. II. Pollen dispersal and heterogeneity in mating success inferred from parent-offspring analysis. Mol Ecol 14: 4441-4452.

Ogden GL (1975). Differential response of two oak species to far inland advection of sea-salt spray aerosol. PhD dissertation Thesis, University of California.

Pavlik BM, Muick PC, Johnson SG, Popper M (1991). Oaks of California. Cachuma Press and the California Oak Foundation: Los Olivos.

Robledo-Arnuncio JJ, Gil L (2005). Patterns of pollen dispersal in a small population of Pinus sylvestris L. revealed by total-exclusion paternity analysis. Heredity 94: 13-22.

Robledo-Arnuncio JJ, Austerlitz F, Smouse PE (in press) Poldisp: a software package for indirect estimation of contemporary pollen dispersal. Mol Ecol Notes (in press).

Shen H, Rudin D, Lindgren D (1981). Study of the pollination pattern in a Scots pine seed orchard by means of isoenzyme analysis. Silvae Genetica 30: 7-15.

Smouse PE, Dyer RJ, Westfall RD, Sork VL (2001). Twogeneration analysis of pollen flow across a landscape. I. Male gamete heterogeneity among females. Evolution 55: 260-271.

Smouse PE, Meagher TR, Kobak CJ (1999). Parentage analysis in Chamaelirium luteum (L.) Gray (Liliaceae): why do some males have higher reproductive contributions? J Evol Biol 12: 1069-1077.

Smouse PE, Sork VL (2004). Measuring pollen flow in forest trees: an exposition of alternative approaches. For Ecol Manage 197: 21-38.

Sork VL, Davis FW, Smouse PE, Apsit VJ, Dyer RJ, Fernández$\mathrm{M}$ JF et al. (2002). Pollen movement in declining populations of California Valley oak, Quercus lobata: where have all the fathers gone? Mol Ecol 11: 1657-1668. 
Sork VL, Nason J, Campbell DR, Fernández-M JF (1999) Landscape approaches to the study of gene flow in plants. Trends Ecology Evol 142: 219-224.

Steinkellner H, Lexer C, Turetschek E, Glossl J (1997). Conservation of (GA)(n) microsatellite loci between Quercus species. Mol Ecol 6: 1189-1194.

Streiff R, Ducousso A, Lexer C, Steinkellner H, Gloessl J, Kremer A (1999). Pollen dispersal inferred from paternity analysis in a mixed oak stand of Quercus robur L. and Q. petraea (Matt.). Liebl. Mol Ecol 8: 831-841.
Tufto J, Engen S, Hindar K (1997). Stochastic dispersal processes in plant populations. Theor Pop Biol 52: 16-26.

Weir BS (1996). Genetic Data Analysis II. Sinauer Associates: Sunderland.

Wolfram S (1999). The Mathematica Book, 4th edn. Wolfram Media/Cambridge University Press: Champaign, IL/CA.

Wright S (1943). Isolation by distance. Genetics 28: 114-138.

Young A, Boyle T, Brown T (1996). The population genetic consequences of habitat fragmentation for plants. Trends Ecol Evol 11: 413-418. 